\title{
IN VITRO MORPHOGENETIC REACTION OF MELISSA OFFICINALIS L.
}

\author{
A.M. Radomir ${ }^{*}$ and R. Stan 1 \\ 1National Research and Development Institute for Biotechnology in Horticulture \\ Ștefănești - Argeș, România \\ * Corresponding author email: radomir.anamaria@yahoo.com
}

\begin{abstract}
Lemon balm (Melissa officinalisL.) is a medicinal plant with a long history in traditional medicine. Classical propagation of this species is inefficient for establishing a good quality clonal plants. The aim of this work was to elaborate an in vitro propagation protocol for $M$. officinalis using apexes and uninodal fragments as explants. The highest multiplication rate (4.7 shoots/explant) was obtained on a MS medium supplemented with $3 \mathrm{mg} / \mathrm{L}$ BAP. A half strength MS medium supplemented with $1 \mathrm{mg} / \mathrm{L}$ NAA was the most effective for in vitro rooting of lemon balmmicroshoots. Micropropagated plants transferred ex vitro showed normal morphology and $95 \%$ survival rate during acclimatization. The results obtained throughout the in vitro regeneration phases confirm that in vitro tissue culture is an efficient method for multiplication of $M$. officinalis.
\end{abstract}

Keywords: lemon balm, micropropagation, growth regulators, multiplication, rooting

\section{INTRODUCTION}

Melissa officinalis L.(lemon balm) is a herbaceous, perennial plant of Lamiaceae family, native to northern Mediterranean region, known for the meliferous and curative properties (Tavares et al., 1996).The aerial part of plant comprises 0.05 to $0.15 \%$ of volatile oil (that contains citronellal, citral, geraniol, linalool), polyphenols, tannins (3 to 6\%), mucilages (12\%), bitter substances etc. The seeds contain fat oil made up of linolenic, linoleic, oleic, palmitic and stearic acids (Ciulei et al., 1993; Schultze et al., 1993; Parvu, 2000; Stanescu et al., 2002; Tita, 2003; Aprostosoaie, 2005). The main action of its active principles, especially of lemon balm volatile oil is spasmolitic, sedative, antiseptic, carminative, choleretic, mild laxative, stomachic, cicatrisant, galactagogue and insecticide (Ciulei et al., 1993; Stanescu et al., 2002; Tita, 2003).

M. officinalis is naturally propagated by seeds or vegetatively and grows easily in farm, but its population is not homozygote and the yield is extremely low. Therefore, its production via cultivation of local populations using traditional methods is not economic (Meftahizade et al., 2010a). The in vitro culture of aromatic and medicinal plants has proved to be an important alternative for rapid multiplication of selected genotypes (Agostini and Echeverrigaray, 2006). In vitro regenerated plants are often healthier than their field propagated clones, this is mainly due to rejuvenation and they are often disease-free plants (Pierik, 1997). Shoot proliferation from apices or axillary buds to produce multiple shoots with root production is now recognized as a viable technique for plant propagation (Tavares et al., 1996). Micropropagation is a valuable method for large scale multiplication of manyplant species, but the appropriate use, type and concentration of growth regulators 
and the combination of culture medium salts that allows fast, efficient development of theinitial explants are crucial in tissue culture techniques (Schuchovski and Biasi, 2019). Several researchers work to standardize the optimum concentrations of growth regulators for shoot proliferation and regeneration of lemon balm (Schultze et al., 1993; Tavares et al., 1996; Meszaros, 1999; Da Silva et al., 2005; Ghiorghita et al., 2005; Meftahizade et al., 2010 a, b).

Considering the medicinal importance of $M$. officinalis we intended to find out some information regarding its in vitro behavior, the reaction of explants on varied hormonal formulae and the possibility of identifying an effective micropropagation technology.

\section{MATERIALS AND METHODS}

\section{"In vitro" culture initiationphase}

The explants used for the initiation of in vitro cultures consisted of apexes and uninodal fragments from actively growing shoots of $M$. officinalis mother stock plants. The shoots were first rinsed in tap water and were sterilized in 6\% calcium hypochlorite solution for 10 minutes, followed bythree rinses using sterile distilled water.The stem segments were then cut with a sterile scalpel blade into smaller segments (1-1.5 cm long), each with one node used as explants. The explants were placed vertically on a plain MS medium (Murashige and Skoog, 1962) and maintained as shoot tip and single node cultures until plant material was sufficient for further experiments. The inoculation of explants was carried out under aseptic conditions using a laminar air flow hood.At this stage of the experiment, as well as at subsequent stages, the medium was supplemented with $40 \mathrm{~g} / \mathrm{L}$ glucose, $32 \mathrm{mg} / \mathrm{L} \mathrm{NaFeEDTA}$ (as iron source) and $7 \mathrm{~g} / \mathrm{L}$ agar (for solidification of culture media).The culture media were sterilized by autoclaving at $120^{\circ} \mathrm{C}$ for 20 minutes. Before autoclaving, the $\mathrm{pH}$ of the medium was adjusted to 5.6-5.8 with $1 \mathrm{~N} \mathrm{KOH}$ or $1 \mathrm{~N} \mathrm{HCl}$.All cultures were transferred in a growth room with controlled conditions at $22-24^{\circ} \mathrm{C}$, a 16 hourslight photoperiodat $3000 \mathrm{~lx}$.

\section{"In vitro" multiplication phase}

Shoot proliferation was induced on a full strength MS medium supplemented with different type of cytokinins (BAP-benzylaminopurine, KIN-kinetin) at various concentrations $(0,1,1.5$, 2 and $3 \mathrm{mg} / \mathrm{L}$ ). Subculturing was performed every four weeks.The number of shoots per explant and shoot length was monitored as growth parameters. Every treatment was performed in three repetitions.

\section{"In vitro" rooting phase}

Individual microshoots were transferred in a half strength MS medium, supplemented with three different auxins (NAA-naphthalenacetic acid, IAA-indolylacetic acid, IBAindolylbutyric acid) at concentration of $0,0.5$ and $1 \mathrm{mg} / \mathrm{L}$. After four weeks of culturing, the rooting rate (ratio between the number of shoots at which the rhizogenesis process took place and the total number of shoots transferred to the rooting culture medium) was evaluated. Every treatment was performed in three repetitions.

\section{Acclimatization phase}

The in vitro rooted plantlets were removed from culture medium and their roots were washed in running tap water and then transplanted in pills of peat (Jiffy) for acclimatization to ex vitro conditions. Since lemon balm leaves are very sensitive to water loss and the loss of the water content of plantlets is irreversible, it was necessary to provide a high humidity environment by placing the plants under a plastic foil tunnel and spraying them with water until they start to harden.The percentage of acclimatized plants (the ratio between the number of viable plants and the total number of plants transferred ex vitro) was calculated after four weeks.The acclimatized plants were then transplanted in $0.5 \mathrm{~L}$ plastic pots for 
fortification and maintained in a non-heated greenhouse for further growth and development.

\section{Statistical analysis}

The experimental design was planed in triplicates for each treatment.Statistical interpretation of the data was done using SPSS 10 for Windows program. Differences between variantscompared to the controlwere analyzed with One Way ANOVA - LSD, considering to be significant at $\mathrm{P}<0.05$.

\section{RESULTS AND DISCUSSIONS}

\section{Morphogenetic reaction of explants in the initiation phase of"in vitro" culture}

Culture initiation is the most important stageof micropropagation in different plant species. One of the essential conditions on which depends the success of initiation and maintenance of a cell culture is that of ensuring asepsis. The method of the biological material sterilization varies depending on the origin of the material, the physiological state and the type of explant material.In the present study, for in vitro culture initiation were used as explants apexes and uninodal fragmentssampled from actively growing shoots. Our observations highlighted the fact that including the lemon balm in this culture system does not pose particular problems, use of calcium hypochlorite (6\% solution for 10 minutes) for biological material sterilization proved to be efficient.The use of a plain MS basal medium induced the successfulshoot development and microplantproduction, which were then used for experimentation of $M$. officinalis explants for morphogenetic reaction on different concentration of cytokinins (Figure 1).

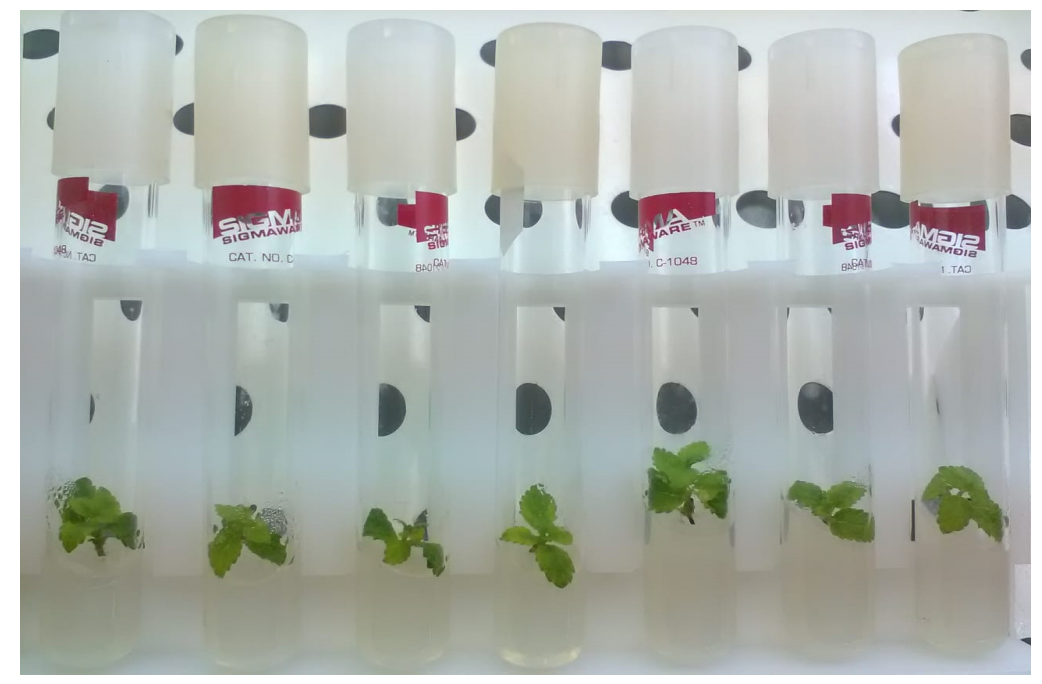

Figure 1. M. officinalismicroplants regenerated on plain MS medium,four weeks after in vitro cultureinitiation

\section{Effect of cytokinintype and concentration on "in vitro"shoot proliferation}

The current experimentswere carried out using 6-benzylaminopurine (BAP) and kinetin (KIN).BAP showed better response regarding the development of shoots than kinetin. Kinetin produced a lower number of shoots per explant and shoot length, compared to BAP treatments.The results obtained revealed that the maximum number of shoots per explant was obtained on MS medium supplemented with $3 \mathrm{mg} / \mathrm{LBAP}$ (4.7 shoots/explant)followed by the medium with $2 \mathrm{mg} /$ LBAP ( 4.5 shoots/explant)(Figure 2 ). This is coinciding with the previous observations revealingthat the increase of BAP 
concentration gave greatest efficiency in shoots number (Tavares et al., 1996; Sato et al., 2005). The high efficiency of BAP in shoot proliferation resulted in several medicinal plant species which are well documented in the literature (Mikulik, 1999; Rout et al., 2000; Fracaro and Echeverrigary, 2001; Kamstaityte and Stanys V., 2004; Rout, 2004; Balogun et al., 2007; Bohidar et al., 2008; Kalimuthu et al., 2010).

This fact can be explained that cytokinins, especially at high concentrations, overcome theapical dominance and inhibit the effect of apical peak on side buds, stimulating the proliferation of axillary shoots from these buds (Mikulik, 1999; Fracaro and Echeverrigary, 2001).

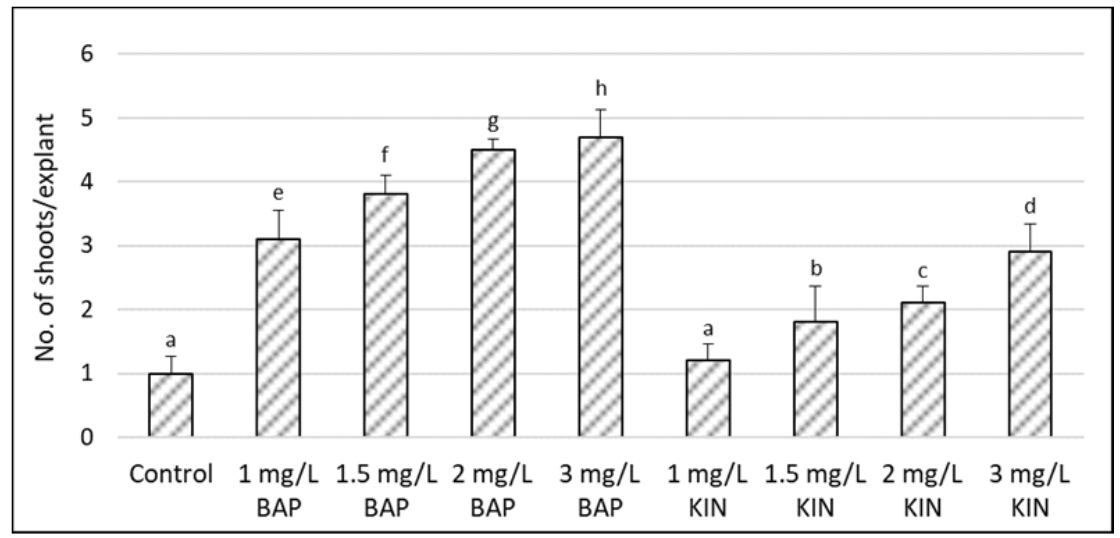

Figure 2. The influence of type and concentration of cytokinin on the number of shoots per explant of M. officinalis. The mean values are accompanied by their corresponding standarddeviations; letters indicate significance of differences as compared to the control at $\mathrm{P}<0.05$

Tavares et al. (1996) also reported that higher concentration of BAP induced more but smaller shoots, suggesting an inverse relation between the number of shoots and their elongation. The treatment of $3 \mathrm{mg} / \mathrm{L}$ BAP induced the largest number and the longest shoots. These results are in concordance with the results obtained by Gulati and Jaiwal (1994) which reported at M. officinalis a direct relationship between the number of shoots and their elongation

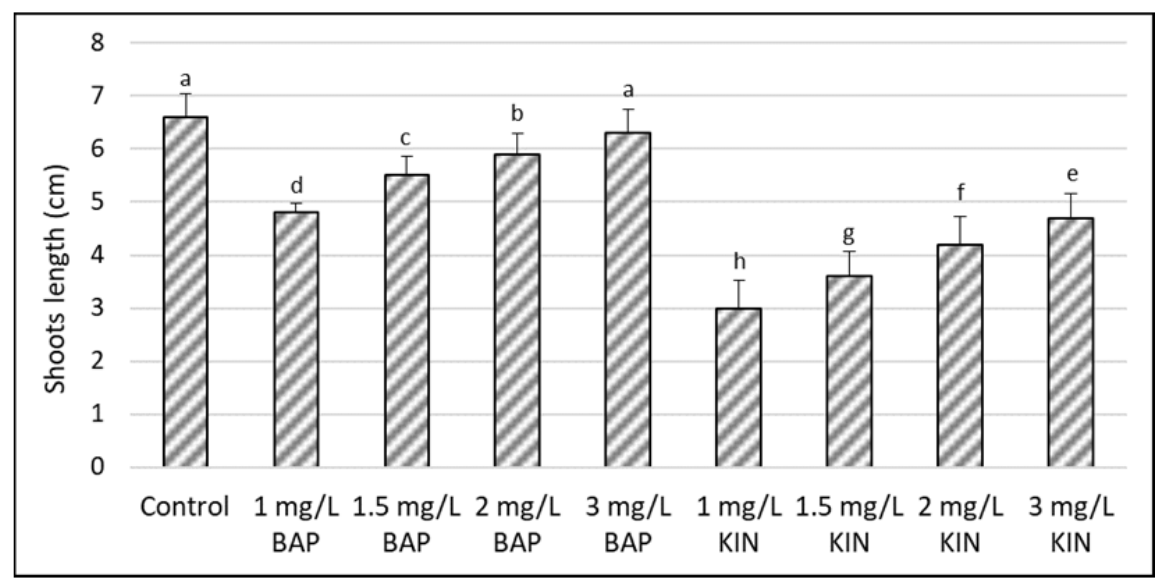

Figure 3. The influence of type and concentration of cytokinin on the shoot lengthof $M$. officinalis.The mean values are accompanied by their corresponding standard deviations; lettersindicate significance of differences as compared to the control at $\mathrm{P}<0.05$ 
On cytokinin-containing media, the average length of the shoots increased with cytokinin concentration. In all experimental variants, the evaluated indicator recorded significant differences compared to the control at $\mathrm{P}<0.05$ except of the variant in which the culture medium was supplemented with $3 \mathrm{mg} / \mathrm{L}$ BAP. In the presence of growth regulators the shoot length was smaller (between 3.0 and $6.3 \mathrm{~cm}$ ) in all cases compared to the control $(6.6 \mathrm{~cm})$ (Figure 3). Sarikhani et al. (2010) achieved good results regenerating lemon balm using MS culturemedia without hormones and induced polyploidy. Ardakani et al. (2003) regenerated M.officinalismicroplants using a MS culture mediumsupplemented with kinetin $(0.2 \mathrm{mg} / \mathrm{L})$, IAA (1 mg/L), 2,4-D (1 mg/L) and coconut juice (15\% v/v).

Described results indicate that MS medium supplemented with $3 \mathrm{mg} / \mathrm{L}$ BAP was the most effective for regenerationof $M$. officinalis shoots, the regenerated shootsbeinglong and vigorous (Figure 4).

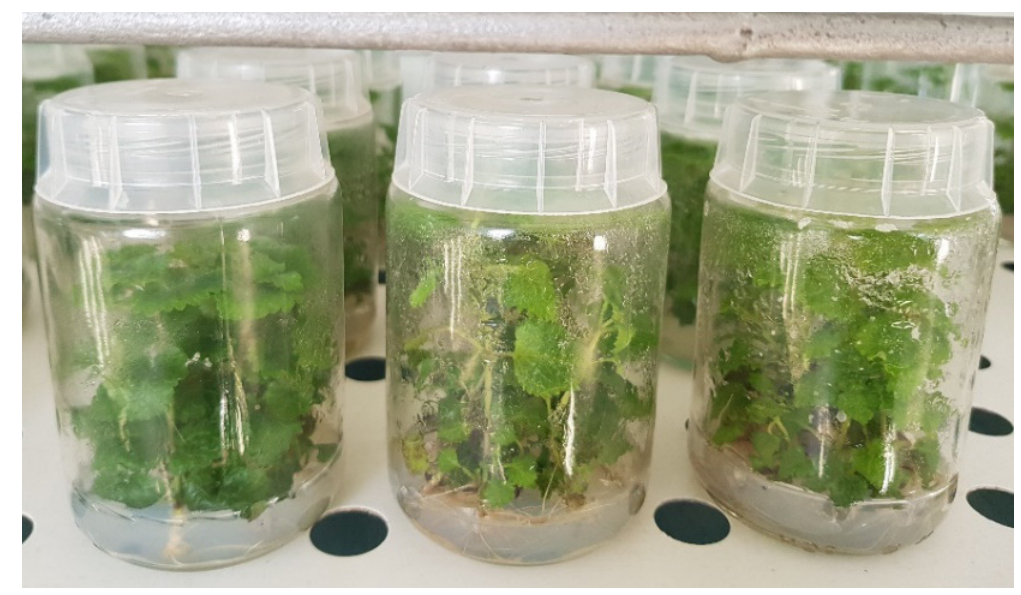

Figure 4. In vitroaxillary shoot proliferation of M. officinalis using a MS medium supplemented with 3 $\mathrm{mg} / \mathrm{L}$ BAP

After four weeks, the regenerated microshoots were transferred to fresh culture medium that supported the regenerative processes by determining a good proliferation of theshoots.From the qualitative point of view, the biological material resulting from the regeneration of explants had a normal morphology, without vitrification aspects, necrosis or callus differentiation.

\section{Effect of auxin type and concentration on "in vitro" rooting of theshoots}

It is known that, in case of in vitro cultures, the auxins are responsible for stimulating root development and cell elongation. The effect of auxins on root formation has been well documented in several plant species (Blakesley and Constantine, 1992; Fracaroand Echeverrigary, 2001). Auxins alone or in combination with very low concentration of cytokinins were effective in induction of root primordia (Pierik, 1997).However, high concentrations of auxinsinfluence the development of callus and inhibition of root development.

In the current study, six variants of rooting medium using NAA, IAA and IBA at 0.5 and $1 \mathrm{mg} / \mathrm{L}$ were experimented plus a control using a half strength MS basal medium. The type and concentration of auxin on theroot formation of $M$. officinalis was evaluated, in four weeks.

The rooting rate of all treatments resulted to a significant increase compared to the control at $\mathrm{P}<0.05$. The highest value on rooting $(96.1 \%)$ was obtained at $1 \mathrm{mg} / \mathrm{L}$ NAA. Application of IBA or IAA resulted in reduced rooting percentage. For all auxins used, the rooting rate increased with increasing the concentration, but roots were also developed in 
an auxin - free medium(40.6\% rooted shoots)(Figures5 and 6).This could be possibly to the presence of high amounts of auxins in lemon balm tissues compared to other medicinal plants.

The results were consistent with those obtained by Tavares (1996), reported that root formation required the presence of NAA in the culture medium.Meftahizade et al. (2010b) reported the development of roots at $96 \%$, using $1 \mathrm{mg} / \mathrm{L}$ NAA, while by using IBA hormone only $64 \%$ of the roots were formed.

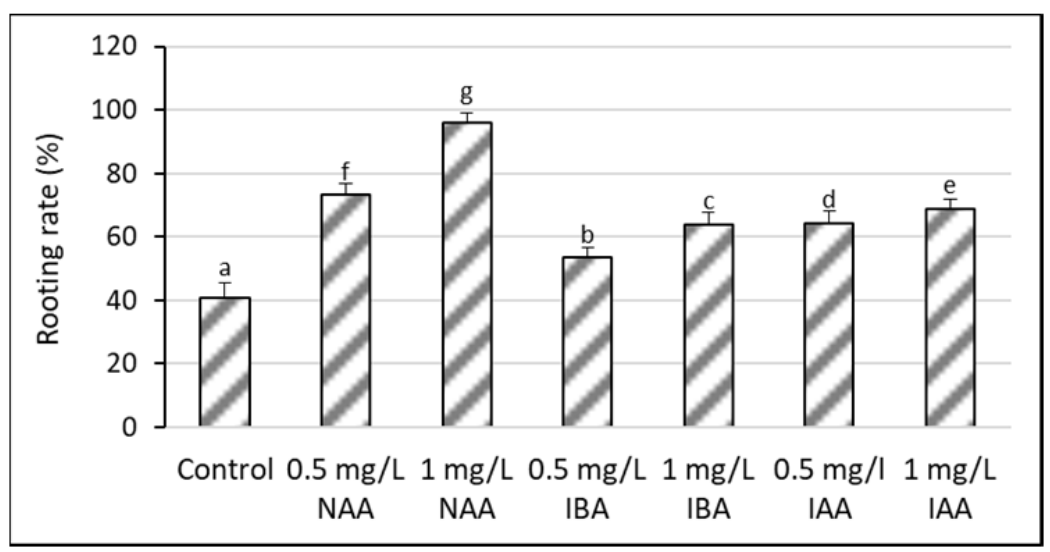

Figure 5. Effect of type and concentration of auxinson the in vitro rooting abilityof $M$. officinalis microshoots.The mean values are accompanied by their corresponding standard deviations;

lettersindicate significance of differences as compared to the control at $\mathrm{P}<0.05$

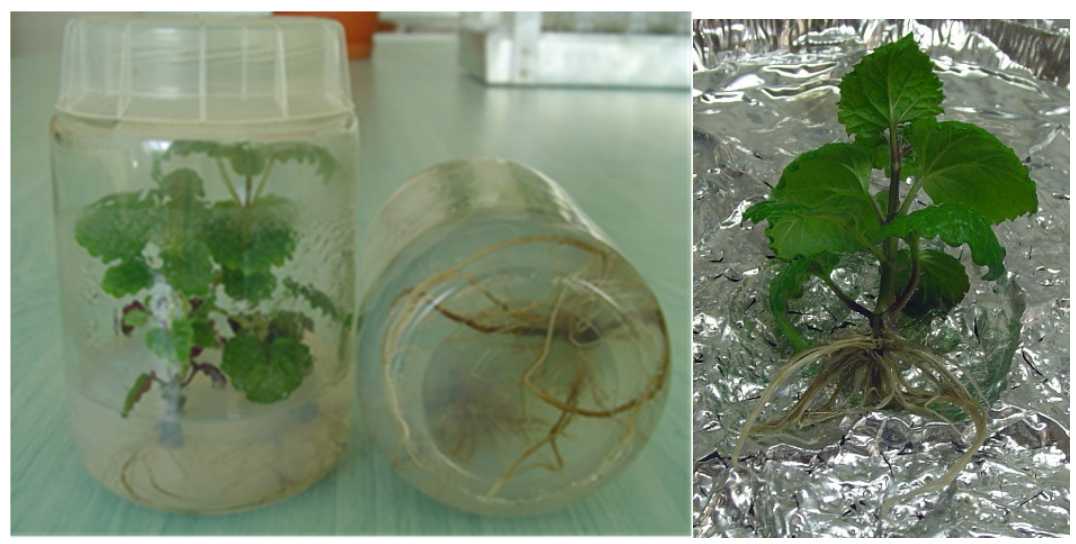

Figure 6. M. officinalis microshoot rooting on $1 / 2 \mathrm{MS}$ medium supplemented with $1 \mathrm{mg} / \mathrm{L}$ NAA

The microplants regenerated in vitrowere characterized by long roots with secondary branches, allowing their transplanting to ex vitro conditions.

\section{Acclimatization of vitroplants to the"ex vitro" conditions}

Acclimatization is the final stage, but most important and necessary for all types of plant micropropagation. Regardless of the in vitro culture method adopted, its success depends on the ability to transfer the plants ex vitro, to an acceptable economic level. This involves the adaptation of in vitro plants to new environmental conditions such as: lower relative humidity, higher light intensity, temperature fluctuations and thestress caused by different diseases.

In vitro regenerated plants had a vigorous root system, supporting a successful passage to the acclimatization phase. 
Due to their thin, the leaves plants frequently suffer water losses and this is the reason why their acclimatization is not easy to accomplish, requiring a more humid atmosphere and a controlled temperature, due to major thermic changes must be avoided. The previously mentioned conditions permitted a more facile accommodation period and diminished losses of biological material, the efficiency of the acclimatization plants regenerated in vitro was $95 \%$.

After the acclimatization and fortification in pots, the plants were transplanted in a greenhouse to continue their growth and development. The plants obtained by in vitro propagation have preserved morphological characteristics of the mother stock plants (Figure 7).

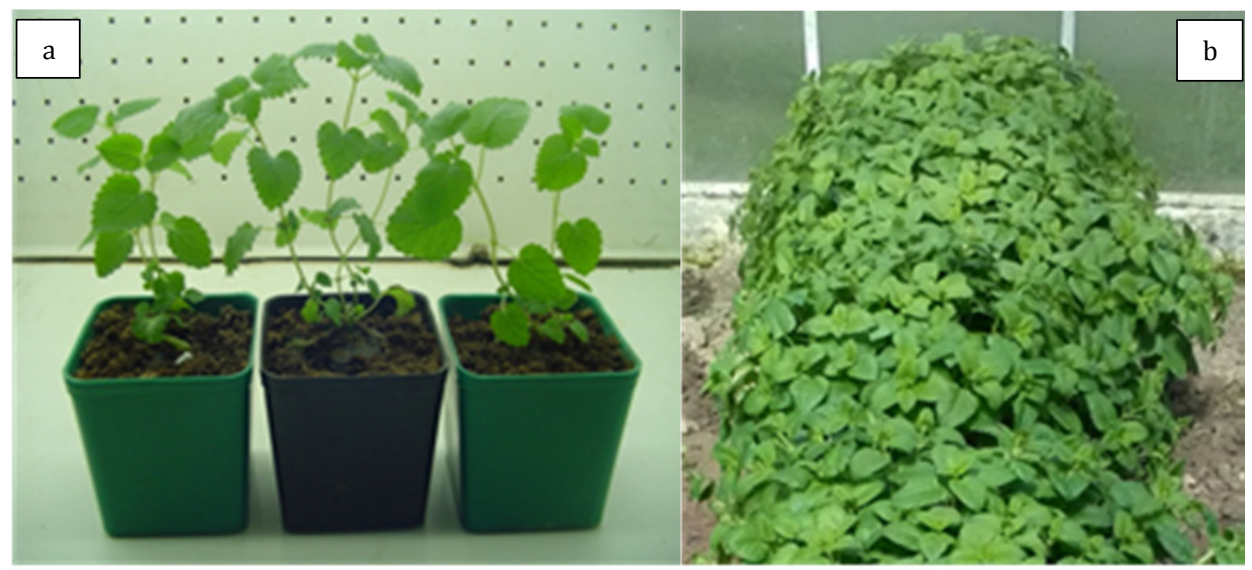

Figure 7.In vitro regenerated lemon balm plants fortified to pots (a) and soil (b)

We conclude that the results obtained throughout in vitro regeneration phases certify that for $M$. officinalis, the micropropagation technique represents an advantageous alternative to the classic methods of propagation, which allows the rapid and massive propagation of high quality clonal plants.

\section{CONCLUSIONS}

The research shows that in vitro shoot multiplication of $M$. officinalis is depending upon the treatment with growth regulators that are used. The newclonal plants obtained by micropropagation have been appeared normal and no morphological variation was shown. The in vitro culture system was successfully established for lemon balmand offers a viable tool for preservation, multiplication and sustainable production of this very valuable medicinal species. This protocol can ensure a stable supply of this commercial crop in a limited time and space, irrespective of seasonal variations and thus meet the global demand for its essential oil. The regenerated plants could also serve as potential sources for the extraction of active compounds for pharmaceutical purposes.

\section{ACKNOWLEDGEMENTS}

The authors would like to thank the National Research and Development Institute for Biotechnology in Horticulture Ștefănești - Argeș from Romania for providing the necessary facilities for the current research work. 


\section{REFERENCES}

1. Agostini, G., and Echeverrigaray, S. (2006). Micropropagation of Cunilaincisa Benth., a potential source of 1,8cineole. Rev. Bras. Pl. Med. Botucatu, 8:186-189.

2. Aprotosoaie, C. (2005). Cercetări privind acțiunea unor pesticide aplicate în cultura plantelor medicinale: aspecte morfologice și biochimice. Teză de doctorat. UMF Gr.T.Popa, Iași, 377.

3. Ardakani, M.R. (2003). Production and maintenance of Melissa officinalis cell cultures and comparison with metabolites produced by plant callus full. Journal of Medicinal Plants, 13: 68-71.

4. Balogun, M.O., Akande, S.R., andOgunbodede, B.A. (2007). Effects of plant growth regulators on callus, shoot and root formation in fluted pumpkin (Telfairiaoccidentalis). Afr. J. Biotechnol., 6:355-358.

5. Blakesley, D., and Constantine, D. (1992). Uptake and metabolism of 6-benzyadenine in shoot cultures of a range of species. Plant Cell Tiss. Org. Cult. 28:183-186.

6. Bohidar, S., Thirunavokkarasu, M., and Rao, T.V. (2008). Effect of plant growth regulators on in vitro micropropagation of garden rue (RutagraveolensL.). Int. J. Integra. Biol. 3:36-43.

7. Ciulei, I., Grigorescu, E., and Stanescu, U. (1993). Plante medicinale, fitochimie și fitoterapie, Ed. Medicală, București, 2: 87-90.

8.Da Silva, S., Sato, A., Luiz, C., Lage, S., Da Silva Sun Gil, R.A., Azevedo, A., andApparecidaEspuibel, M. (2005). Essential oil composition of Melissa officinalis L. in vitro produced under the influence of growth regulators. J. Braz. Chem. Soc., 16:1387-1390.

9. Fracaro, F., and Echeverrigary, S., (2001). Micropropagation of Cunila galioides, a popular medicinal plant of south Brazil. Plant Cell Tiss. Org. Cult. 64: 1-4.

10. Ghiorghita, G.I., Mafteli, D.E.S., andNicuta, D.N. (2005). Investigations on the in vitro morphogenetic reaction of Melissa officinalis L. species. Genet. Biol. Mol. 5:119-125.

11. Gulati, A., and Jaiwal, P.K. (1994). In vitro induction of multiple shoots from shoot tips of mung bean (Vigna radiata (L.) Wilczek). Plant Cell, Tiss. Org. Cult. 29: 199-205.

12. Kalimuthu, K., Vijayakumar, S., Senthilkumar, R., andSureshkumar, M. (2010). Micropropagation of Aloe vera L. - A medicinal plant. Int. J. Biotechnol. Biochem., 6:405-410.

13. Kamstaityte, D., andStanys, V. (2004). Micropropagation of onion (Allium cepa L.). ActaUniversitatisLatviensis, Biol. 676:173-176.

14. Meftahizade, H., Lofti, M., andMoradkhani, H. (2010a). Optimization of micropropagation and establishment of cell suspension culture in Melissa officinalis L. Afr. J. Biotechnol., 9:4314-4321.

15.Meftahizade, H., Moradkhani, H., Naseri, B., Lofti, M., andNaseri, A. (2010b). Improved in vitro culture and micropropagation of different Melissa officinalis L. genotypes. J. Med. Plant. Res., 4:240-246.

16. Meszaros, A., Bellon, A., Pinter, E., and Horvath, G. (1999). Plant cell, tissue and organ culture, 57:149-152.

17. Mikulik, J. (1999). Propagation of endangered plant species by tissue cultures. Biol. 37:27-33.

18. Muraskige, T., and Skoog, F. (1962). A revised medium for rapid growth and bio assays with tobacco tissue cultures. Physiol. Plant, 15(3): 473-497.

19. Parvu, C. (2000). Universul plantelor.Mica enciclopedie. Ed. Enciclopedica, București, 567.

20. Pierik, R.A. (1997). In Vitro Culture of Higher Plants. Kluwer Academic Publishers, Dordrecht, The Netherlands.

21.Rout, G.R., Samantaray, S., and Das, P. (2000). In vitro manipulation and propagation of medicinal plants.Biotechnol. Adv. 18:91-120.

22.Rout, G.R.(2004). Effect of cytokinins and auxins on micropropagation of ClitoriaternateaL. Biol. Lett. 41:2126.

23. Sarikani, H. (2010). In vitro induction of polyploidy herb lemon balm (Melissa officinalis L.). Journal of Medicinal and Aromatic Plants Research of Iran, 26(3):283-295.

24. Sato, A., Dasilva, S., Celso Luiz Salgueiro, L., Rosane Aguiar, S.S.G., and Maria, A.E. (2005). Essential Oil Composition of Melissa officinalis L. in vitro Produced under the Influence of Growth Regulators. J. Braz. Chem. 16: 1387-1390.

25. Schuchovski, C.S., andBiasi, L.A. (2019). In Vitro Establishment of 'Delite'Rabbiteye Blueberry Microshoots. Horticulturae, 5(1):24.

26. Schultze, W., Hose, S., Abou-Mandour, A., and Czygan, F.C. (1993). Biotechnology in agriculture and forestry. Springer-Verlag, Berlin, Heidelberg, 24:242-268.

27. Stanescu, U., Miron, A., Hancianu, M., and Aprotosoaie, C. (2002). Bazele farmaceutice și clinice ale fitoterapiei. Ed. Gr.T.Popa, Iași, 1:360.

28. Tavares, A.C., Pimenta, M.C., and Gonalves, M.T. (1996). Plant. Cell Rep., 15:441-444.

29. Tita, I. (2003). Botanică farmaceutică. Ed. did. și ped., București, 801. 